\title{
SOME EMPIRICAL ISSUES IN RESEARCH ON ACADEMIC DEPARTMENTS: HOMOGENEITY, AGGREGATION, AND LEVEL OF ANALYSIS
}

\author{
V. Jean Ramsey and L. Delf Dodge
}

This study investigated the appropriateness of the academic departmental level of analysis. Homogeneity of faculty members' responses to measures of organiza. tional structure, environmental uncertainty, and task routineness was examined to determine the legitimacy of aggregating those responses to create departmental level variables. Analysis of variance suggested that the structure and environmental uncertainty subscales were measuring departmental level phenomena, but that the task routineness scales were not. Results demonstrate the importance of empirically testing, rather than assuming, levels of analysis in studies of academic departments.

It is generally agreed that academic departments are the basic organizational unit in which most faculty pursue their disciplinary and professional interests and execute the teaching, research, and service function of the university (cf. Peterson, 1976). Departments exert the principal force in the operational definitions of goals and purposes of the university, largely control faculty reward mechanisms, and through both formal and informal mechanisms, are the primary focus of institutional progress and academic achievement (Ikenberry and Friedman, 1972).

Despite the importance of the department as a basic element in the university organizational structure, Peterson (1976) points out that the literature on academic departments is "voluminous," but most is nontheoretical and not empirically based. Dressel et al. (1970) also note that the discussion of the department and its structure in the literature greatly exceeds the facts and generalizations based on systematically gathered evidence.

V. Jean Ramsey, Western Michigan University; L. Delf Dodge, The University of Michigan.

Research in Higher Education (C) Agathon Press, Inc. Vol. 18, No. 2, 1983 
Empirical issues which have, for the most part, been overlooked in research on academic departments include homogeneity, aggregation, and level of analysis. The results of organizational research studies in higher education are greatly influenced by several basic research decisions. Whether to measure constructs of interest at the individual, department, or university level, and how to establish and demonstrate homogeneity of responses prior to aggregating individual responses, are among the more critical issues.

Most researchers consciously choose a specific level (or levels) of analysis before conducting a study. Equally important is demonstrating, through some measure of response homogeneity, that the level one intends to measure is, indeed, the level one has measured. To our knowledge, when the academic department has been used as the unit of analysis, homogeneity of response has been generally assumed, but never demonstrated.

\section{IMPORTANCE OF DEMONSTRATING HOMOGENEITY}

Any aggregation of data measured at the individual level is based on the assumption of homogeneity of organizational members' responses. The problem is two-sided: From which individuals do we gather data if we wish to measure an organizational level variable, and how do we combine their individual scores (Lynch, 1974)? Careful consideration must be given to determining how individuals have reported the same phenomenon before aggregating scores, especially if the measures used are perceptual (Duncan, 1971; Schneider and Bartlett, 1970).

Studies in which group averages, taken across people, are used as summary statistics implicitly assume that individuals' perceptions are in agreement. It is curious that more studies do not test such assumptions of homogeneity prior to aggregating data points into broader measures. Sathe (1978) is not unusual in defending aggregation by simply citing the practices of others: "Following Hall (1963), Duncan (1971), Pennings, (1973), and Lynch (1974), departmental scores for this study were obtained by assigning equal weight to the score of each individual" (pp. 231-232). Leifer and Huber (1977), on the other hand, are only one example of researchers who have aggregated data without explanation or apology: "The unweighted mean scores on each measure were then averaged to obtain an organicness score for each individual's work unit. The average of these organicness scores for all individuals in a unit was used as the organicness score for that unit" (p. 240). One of the reasons for the general omission of tests of homogeneity may be that there is not a simple, well-agreed upon method of demonstrating it.

\section{METHODS OF DEMONSTRATING HOMOGENEITY}

While the importance of demonstrating homogeneity is agreed upon in 
principle, there is little discussion of methods of investigating the degree of response homogeneity in a particular sample. That is, how does one demonstrate that an organization or subunit-level variable is not simply a random collection of individual responses? The most common method used to demonstrate that aggregated scores of organizations and departments reflect properties of the described organization, and not merely idiosyncratic responses, is analysis of variance. It has, however, been used in somewhat different ways.

Duncan (1972) used one-way analysis of variance computed across individuals in a given decision unit to look for significant differences among individual perceptions before individual scores were pooled to produce decision unit scores. Pennings (1973) used one-way analysis of variance on subscale measures of organizational structure, as well as multivariate analysis of variance on subscale clusters, to demonstrate homogeneity. He also attempted to establish response homogeneity by computing rank order correlations between the mean scores of supervisor and subordinate subsamples in each of the 10 organizations studied.

Lynch (1974) also combined the use of analysis of variance and rank-order correlations to demonstrate homogeneity. Analysis of variance was used to test whether a person's social position or length of time in his or her position influenced responses. In addition, a rank ordering of departments, using aggregated responses of only those respondents who had masters' degrees in library science, was compared with the rank order when all respondents were aggregated.

Irrespective of the technique used, it would seem important to establish homogeneity prior to aggregating data when conducting organizational research in any setting. The purpose of this study was to investigate the homogeneity of faculty members' responses to measures of organizational structure, environmental uncertainty, and task routineness in order to determine whether aggregating responses to departmental level variables was empirically valid.

\section{METHOD}

Data were collected in 21 academic departments of two colleges in a single university. Questionnaires were mailed to all faculty within these departments. A response rate of $52 \%$ resulted in 152 faculty members' responses being included in the data analyses.

\section{Measures}

Van de Ven and Delbecq's (1974) measures of task routineness and Duncan's (1971) measures of environmental uncertainty and structure were used. 
Four subscales measured structure (hierarchy of authority, impersonality, participation in decision making, rules and procedures), two measured environmental uncertainty (lack of information, knowledge of outcomes), and two measured task routineness (task difficulty, task variability).

Two sets of measures were used for each of the three major concepts of interest in this study. Faculty were asked about the predictability and variability of their "job" of teaching and their "job" of research. Faculty were also asked to respond to questions concerning environmental uncertainty in two contexts: once in connection with the factors outside the department they took into consideration in making decisions about their teaching activities, and once in connection with the factors outside the department they took into consideration in making decisions about their research activities. Similarly, faculty were asked to respond to questions concerning the department's decision-making structure twice: once in connection with decisions made regarding teaching activities, and a second time in connection with decisions made in the course of their research activities.

Hierarchy of authority was measured by asking faculty whether (1) they could usually go ahead without checking with their department heads if they felt they had the right approach to carrying out their jobs, or (2) they had to check with the department head before doing almost anything. Impersonality was tapped with items asking respondents how often they (1) were likely to express their decisions openly in research or teaching decision situations, and (2) were encouraged to speak their minds even if it meant disagreeing with the department head. In order to measure participation in decision making, faculty and department heads were asked whether (1) most faculty in the department had a voice in teaching- or research-related decisions, (2) they were encouraged to make suggestions, (3) the department head sought their advice before decisions were made, (4) the department head usually made decisions alone, or (5) they played an active role in making decisions. The existence of rules and procedures was identified by asking faculty members whether they felt that (1) there were rules and procedures for handling any kind of problems which might arise in making teaching- or research-related decisions, and (2) the same rules and procedures were usually followed. Lack of information regarding environmental factors associated with a given decision-making situation was measured by asking respondents (1) how often they had the necessary information about external factors to understand their expectations, (2) how often the information was adequate, (3) how difficult it was to get the necessary information, (4) how difficult it was to obtain additional information, (5) how hard it was to determine what the outcome of decisions would be before they were made. Knowledge of outcomes of decisions was measured by asking (1) how often faculty were able to predict reactions of external factors to decisions, and (2) how difficult it was to 
know what the reactions would be before decisions were made.

Task difficulty was measured by asking respondents (1) how sure they were as to what the results of their teaching or research efforts would be, (2) how long it took to know whether their efforts were successful, (3) the extent to which there was a clearly defined body of knowledge or subject matter to guide them in their teaching or research, and (4) how often they encountered specific but difficult problems they didn't know how to solve. Task variability was measured by asking respondents about (1) the similarity of methods followed for dealing with classes or categories of people, problems, or activities; and (2) the extent to which faculty in the department did the same "job" in the same way most of the time.

Response categories for all items varied along seven-point scales. Items were reverse-scored where necessary, so higher scores indicate a more certain environment, a more routine task, or a higher degree of structure.

\section{Scale Development}

Item-to-total correlations were used to determine which items could be included in each of the subscales. Correlational analyses (per Campbell and Fiske, 1959) were then used to determine which subscales could be combined into overall structural, environmental uncertainty, and task routineness scales (Ramsey, 1979). The structures and environments surrounding teaching and research decisions were perceived by faculty to be quite different. There was little difference in routineness, however, between the tasks of teaching and research. Instead, measures of research and teaching task difficulty correlated, as did measures of research and teaching task variability. The dimensions of lack of information and knowledge of outcomes correlated with one another, within the research and teaching task classifications, to form overall indices of environmental uncertainty. The structural dimensions of hierarchy of authority, impersonality, and participation in decision making clustered and could be combined into overall indices of departmental structure. The rules and procedures dimensions split out from the other structure subscales and were kept separate in subsequent analyses. Reliability coefficients (Cronbach's alpha) of the final scales were acceptable (Table 1). Analysis of variance was used on items and scales to examine the homogeneity of departmental members' responses.

\section{RESULTS}

The intent of this study was to test the viability of aggregating items and subscales to create subunit level measures of organization structure, environmental uncertainty, and task routineness in an academic setting. Homogen- 
TABLE 1. Scale Reliabilities

\begin{tabular}{|c|c|c|}
\hline & $\alpha$ & No. of items \\
\hline Structure $1^{a}$ (teaching) & .83 & 9 \\
\hline Structure 1 (research) & .88 & 9 \\
\hline Structure $2^{b}$ (teaching) & .68 & 2 \\
\hline Structure 2 (research) & .78 & 2 \\
\hline Environmental uncertainty (teaching) & .87 & 7 \\
\hline Environmental uncertainty (research) & .85 & 7 \\
\hline Task difficulty (teaching and research) & .57 & 8 \\
\hline Task variability (teaching and research) & .63 & 4 \\
\hline
\end{tabular}

"Structure 1 includes the dimensions of hierarchy of authority, impersonality, and participation in decision making.

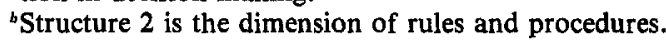

eity of subject responses within and between departments was examined using analysis of variance.

Where $F$ ratios are not significant, equal or greater variance exists in responses within departments than between departments. This could be interpreted as an indication that departmental members' responses are not homogeneous, i.e., there is a great deal of variation in departmental members' responses to the same question. Alternative interpretations are that the variables are unable to discriminate between departments or that significant differences do not exist across departments on these variables.

One-way analysis of variance was first used on each of the items contained in the structure, environmental uncertainty, and task routineness scales, Results of the analyses of variance of the structural variables were mixed (Table 2). In general, the structural measures did not seem to discriminate between departments well. Only the variables included in the teaching hierarchy of authority dimension and the research impersonality dimension were consistently significant. The variables included in the teaching rules and procedures dimension were consistently nonsignificant. The research structural measures did, however, seem to discriminate between departments slightly better than did the teaching structural variables.

The results of one-way analyses of variance on items measuring environmental uncertainty are similarly mixed (Table 3). It would seem that either the variables measuring environmental uncertainty are unable to discriminate between departments or that there are few significant differences across departments on these variables. Finally, the results of the analyses of variance of task routineness items appear in Table 4. Again, results are mixed. About half of the variables are significantly different across departments.

Because results of the one-way analyses of variance of single variables 
TABLE 2. One-Way Analysis of Variance: Structural Variables

\begin{tabular}{lcccrrr}
\hline & \multicolumn{2}{c}{$\begin{array}{c}\text { Mean square } \\
\text { between } \\
\text { departments }\end{array}$} & $\begin{array}{c}\text { Mean square } \\
\text { within } \\
\text { departments }\end{array}$ & $F$ & Sig. \\
\hline Teaching hierarchy & 1 & 3.59 & 2.22 & 1.62 & .06 \\
Teaching impersonality & 2 & 1.86 & 1.09 & 1.70 & .04 \\
& 1 & 1.97 & 2.27 & .87 & .63 \\
Teaching participation & 2 & 3.46 & 1.81 & 1.02 & .02 \\
& 1 & 3.26 & 1.14 & 2.85 & .00 \\
& 2 & 1.81 & 1.89 & .96 & .51 \\
Teaching rules & 3 & 4.83 & 3.56 & 1.36 & .16 \\
& 4 & 1.92 & 1.47 & 1.31 & .19 \\
Research hierarchy & 5 & 2.46 & 2.04 & 1.21 & .26 \\
Research impersonality & 1 & 2.10 & 2.67 & .79 & .72 \\
Research participation & 2 & 2.11 & 2.30 & .92 & .56 \\
& 1 & 2.36 & 1.78 & 1.33 & .17 \\
& 2 & 4.66 & 2.80 & 1.66 & .05 \\
& 1 & 3.95 & 2.03 & 1.94 & .02 \\
& 2 & 4.11 & 2.12 & 1.94 & .02 \\
& 2 & 5.55 & 2.15 & 2.58 & .00 \\
& 3 & 3.22 & 2.31 & 1.40 & .14 \\
Research rules & 3.70 & 3.29 & 1.12 & .34 \\
& 4 & 5.33 & 1.69 & 3.16 & .00 \\
& 5 & 4.94 & 3.01 & 1.64 & .05 \\
& 1 & 3.65 & 2.46 & 1.48 & .10 \\
& 2 & 2.28 & 2.44 & .94 & .54 \\
\hline
\end{tabular}

were mixed, and because the variables are not independent, the next step was to examine one-way analyses of variance of the scales (Table 5). Overall, the combined scales do a better job of differentiating the departments than do the subscales.

As before, the results of the one-way analyses of variance are mixed, but a pattern can be clearly detected. The combined measures of hierarchy of authority, impersonality, and participation in decision making do appear to be tapping departmental-level phenomena, as do the measures of environmental uncertainty surrounding teaching decisions. On the other hand, measures of rules and procedures and task routineness are unable to discriminate across departments at a significant level.

\section{DISCUSSION}

It would seem warranted to aggregate (to the departmental level) faculty responses to the three structure dimensions. Measures of hierarchy of author- 
TABLE 3. One-Way Analysis of Variance: Environmental Uncertainty Variables

\begin{tabular}{lccccc}
\hline & Item & $\begin{array}{c}\text { Mean square } \\
\text { between } \\
\text { departments }\end{array}$ & $\begin{array}{c}\text { Mean square } \\
\text { within } \\
\text { departments }\end{array}$ & $F$ & Sig. \\
\hline Teaching lack of & 1 & 3.78 & 1.57 & 2.41 & .00 \\
$\quad$ information & 2 & 4.39 & 1.97 & 2.23 & .00 \\
& 3 & 3.17 & 2.69 & 1.18 & .28 \\
& 4 & 4.42 & 2.17 & 2.04 & .01 \\
Teaching knowledge of & 5 & 2.12 & 2.11 & 1.01 & .46 \\
outcomes & 1 & 2.82 & 2.25 & 1.26 & .22 \\
Research lack of & 2 & 2.29 & 1.76 & 1.31 & .19 \\
information & 1 & 3.47 & 2.18 & 1.59 & .07 \\
& 2 & 2.16 & 2.20 & .98 & .49 \\
& 3 & 2.28 & 2.76 & .82 & .68 \\
Research knowledge of & 4 & 1.80 & 3.01 & .60 & .91 \\
outcomes & 5 & 2.34 & 2.15 & 1.09 & .37 \\
& 1 & 3.01 & 2.12 & 1.42 & .13 \\
& 2 & 2.48 & 2.20 & 1.13 & .33 \\
\hline
\end{tabular}

ity, impersonality, and participation in decision making as a composite scale do seem to be departmental level measures of structure which differentiate between departments. That rules and procedures do not differentiate departments is not unexpected: the college or university may be the source of operating rules and procedures rather than their being department-specific.

TABLE 4. One-Way Analysis of Variance: Task Routineness Variables

\begin{tabular}{|c|c|c|c|c|c|}
\hline & Item & $\begin{array}{c}\text { Mean square } \\
\text { between } \\
\text { departments }\end{array}$ & $\begin{array}{c}\text { Mean square } \\
\text { within } \\
\text { departments }\end{array}$ & $F$ & Sig \\
\hline \multirow[t]{4}{*}{ Teaching task difficulty } & 1 & 3.90 & 2.33 & 1.67 & .05 \\
\hline & 2 & 1.47 & 1.78 & .83 & .63 \\
\hline & 3 & 3.10 & 1.50 & 2.10 & .01 \\
\hline & 4 & 2.06 & 1.39 & 1.49 & .10 \\
\hline \multirow[t]{4}{*}{ Research task difficulty } & 1 & 3.88 & 2.21 & 1.75 & .03 \\
\hline & 2 & 4.52 & 1.37 & 3.31 & .00 \\
\hline & 3 & 2.62 & 1.45 & 1.81 & .03 \\
\hline & 4 & 3.52 & 1.71 & 2.06 & .01 \\
\hline \multirow[t]{2}{*}{ Teaching task variability } & 1 & 1.51 & 1.59 & .95 & .53 \\
\hline & 2 & 2.35 & 2.06 & 1.14 & .32 \\
\hline \multirow[t]{2}{*}{ Research task variability } & 1 & 1.99 & 1.50 & 1.33 & .18 \\
\hline & 2 & 3.86 & 1.80 & 2.14 & .01 \\
\hline
\end{tabular}


TABLE 5. One-Way Analysis of Variance: Indices

\begin{tabular}{|c|c|c|c|c|}
\hline & $\begin{array}{c}\text { Mean square } \\
\text { between } \\
\text { departments }\end{array}$ & $\begin{array}{c}\text { Mean square } \\
\text { within } \\
\text { departments }\end{array}$ & $F$ & Sig. \\
\hline Structure $1^{a}$ (teaching) & 1.41 & .81 & 1.75 & .04 \\
\hline Structure 1 (research) & 2.53 & 1.14 & 2.22 & .01 \\
\hline Structure $2^{b}$ (teaching) & 1.59 & 1.89 & .84 & .66 \\
\hline Structure 2 (research) & 2.54 & 1.98 & 1.28 & .21 \\
\hline Environmental uncertainty (teaching) & 2.58 & 1.08 & 2.39 & .00 \\
\hline Environmental uncertainty (research) & 1.54 & 1.15 & 1.34 & .17 \\
\hline Task difficulty & .55 & .40 & 1.37 & .15 \\
\hline Task variability & .86 & .86 & 1.00 & .47 \\
\hline
\end{tabular}

${ }^{a}$ Structure 1 includes the dimensions of hierarchy of authority, impersonality, and participation in decision making.

${ }^{b}$ Structure 2 is the dimension of rules and procedures.

Environmental uncertainty surrounding teaching decisions also seems to be a departmental-level scale. Responses concerning the environmental uncertainty surrounding research decisions should, however, be aggregated only with great caution. The research environment appears to be perceived by faculty at an individual rather than departmental level. Individual faculty vary in their perceptions of the uncertainty of their research environments, even though they are members of the same department.

Task routineness dimensions do not appear to be measuring departmental level phenomena. Again, faculty may view their tasks of teaching and research as individual rather than departmental endeavors. The dimensions do not discriminate between departments.

Analyses of variance indicated, then, that one could cautiously aggregate the subscales of structure (hierarchy of authority, impersonality, participation in decision making) and environmental uncertainty (lack of information, knowledge of outcomes), but not the task routineness subscales. These results were surprising since the appropriateness of the academic departmental level of analysis has not been seriously questioned. Nevertheless, the measures used in this study, although reliable, did not differentiate departments especially well.

This is in contrast to the ability of the measures to differentiate departments of a multiline insurance company (Sathe, 1975) and decision units in research and development and manufacturing organizations (Duncan, 1972). One should view the findings of the present study as raising a flag of caution for organizational researchers. When borrowing measures and using them in new settings, one must check not only the reliability and validity of the meas- 
ures, but also the legitimacy of aggregating them.

Further work needs to be done, perhaps using profile analysis, to investigate similarities of and differences between academic departments. If similar departments were clustered or combined on the basis of some theoretical premise, the measures might do a better job of discriminating between departmental groups. Lodahl and Gordon's (1972) use of the concept of paradigm development, rather than the arbitrary boundaries of academic departments defined by the university's organization chart, is a step in this direction.

Further thought and research need to be devoted to the issue of investigating and demonstrating level of analysis before aggregating individual responses in organizational research. Homogeneity, aggregation, and level of analysis issues present no more of a problem for research in higher education than for research in other types of organizations. But since academic departments are such critical organizational units in universities, we need to be especially careful to check, when conducting studies of their structures and processes, that we are, in fact dealing with departmental level phenomena. If our measures do not differentiate departmental from individual responses, we may advance our knowledge of individual faculty, but not of academic departments. It is, therefore, imperative that much more attention be given to homogeneity assessment in organizational research in higher education.

\section{REFERENCES}

Campbell, D. T., and Fiske, D. W. Convergent and discriminant validation by the multi-trait-multimethod matrix. Psychological Bulletin, 1959, 56, 81-105.

Dressel, P. L., Johnson, F. C., and Marcus, P. M. The Confidence Crisis: An Analysis of University Departments. San Francisco: Jossey-Bass, 1970.

Duncan, R. B. The effects of perceived environmental uncertainty on organization decision unit structure. Unpublished doctoral dissertation, Yale University, 1971.

Duncan, R. B. Characteristics of organizational environmental uncertainty. Administrative Science Quarterly, 1972, 17, 313-327.

Hall, R. N. The concept of bureacracy: an empirical assessment. American Journal of Sociology, 1963, 69, 32-40.

Ikenberry, S. O., and Friedman, R. C. Beyond Academic Departments. San Francisco: Jossey-Bass, 1972.

Leifer, R. P., and Huber, G. P. Relations among perceived environmental uncertainty, organization structure, and boundary-spanning behavior. Administrative Science Quarterly, 1977, 22, 235-247.

Lodahl, J. B., and Gordon, G. The structure of scientific fields and the functioning of university graduate departments. American Sociological Review, 1972, 37, 57-72.

Lynch, B. D. An empirical assessment of Perrow's technology construct. Administrative Science Quarterly, 1974, 19, 338-356. 
Pennings, J. B. Measures of organizational structure: a methodological note. American Journal of Sociology, 1973, 79, 686-704.

Peterson, M. W. The academic department: perspectives from theory and research. In F. N. Kerlinger and J. B. Carroll (Eds.), Examining Departmental Management. New Directions for Institutional Research, 1976, Vol. 10, pp. 21-38.

Ramsey, V. J. Organizational structure of academic departments as a function of environmental uncertainty or task routineness: methodological and measurement issues. Unpublished doctoral dissertation, The University of Michigan, 1979.

Sathe, V. Duncan's structural adaption model: a theoretical extension and empirical test. In Proceedings of the Thirty-Fifth Annual Meeting of the Academy of Management, 1975.

Sathe, V. Institutional versus questionnaire measures of organizational structure. Academy of Management Journal, 1978, 21, 227-238.

Schneider, B., and Bartlett, C. J. Individual differences and organizational climate II: measurement of organizational climate by the multi-trait, multi-rater matrix. Per sonnel Psychology, 1970, 23, 493-512.

Van de Ven, A. H., and Delbecq, A. L. A task contingent model of work-unit structure. Administrative Science Quarterly, 1974, 19, 183-197.

Received December 4, 1981 